\title{
MAKING ASSET INVESTMENT DECISIONS FOR WASTEWATER SYSTEMS THAT INCLUDE SUSTAINABILITY
}

\author{
Richard Ashley ${ }^{\mathrm{a}}$, David Blackwood ${ }^{\mathrm{b}}$, David Butler ${ }^{\mathrm{c}}$, Paul Jowitt ${ }^{\mathrm{d}}$, John Davies ${ }^{\mathrm{e}}$, \\ Heidi Smith ${ }^{\dagger}$, Daniel Gilmour ${ }^{\mathrm{g}}$, Crina Oltean-Dumbrava ${ }^{\mathrm{h}}$
}

\begin{abstract}
Effective Integrated Water Management (IWM) is a key component of the World Water Vision and the way in which aspirations for water equity may be realized. Part of the vision includes the promotion of sustainability of water systems and full accountability for their interaction with other urban systems. One major problem is that 'sustainability' remains an elusive concept, although those involved with the provision of urban wastewater systems now recognise that decisions involving asset investment should use the triple bottom line' approach to society, the economy and the environment. The Sustainable Water industry Asset Resource Decisions (SWARD) project has devised a flexible and adaptable framework of decision support processes that can be used to include the principles of sustainability more effectively. Decision mapping conducted at the outset of the project has shown that only a narrow range of criteria currently influence the outcome of asset investment decisions. This paper addresses the concepts of sustainability assessment and presents two case studies that illustrate how multi-criteria decision support systems can
\end{abstract}

\footnotetext{
a Professor, Pennine Water Group, Department of Civil and Structural Engineering, University of Sheffield, Mappin Street, Sheffield S1 3JD

${ }^{\mathrm{b}}$ Senior Lecturer, Urban Water Technology Centre, University of Abertay Dundee, Bell Street, Dundee DD1 1HG

${ }^{c}$ Professor, Centre for Water Systems, University of Exeter, North Park Road, Exeter, EX4 4QF

${ }^{\mathrm{d}}$ Professor, School of the Built Environment, Heriot-Watt University, Edinburgh EH14 4AS

${ }^{\mathrm{e}}$ Head of Civil Engineering, School of Science and the Environment, Coventry University, Coventry CV1 5FB

${ }^{f}$ Environment Officer, Environment Unit, Kirklees Metropolitan Council, Huddersfield HD1 1JY

${ }^{9}$ Research Officer, Urban Water Technology Centre, University of Abertay Dundee, Bell Street, Dundee DD1 1HG

${ }^{\mathrm{h}}$ Senior Lecturer, School of Engineering, Design and Technology, University of Bradford, Bradford BD7 1DP
} 
enhance the assessment of the relative sustainability of a range of options when decisions are being made about wastewater asset investment.

\section{Introduction}

Water service providers are faced with increasingly complex objectives and demands when making asset investment decisions. Additionally, over the last decade, the need to ensure the sustainability of all development activity and the key role of water service provision within this has been recognised (e.g. ASCE/UNESCO, 1998; Cosgrove and Rijsberman, 2000; Lundie et al, 2005). One of the major outcomes of the 2002 World Summit on Sustainable Development was a 'Framework for Action on Water and Sanitation', which outlined nine action areas. Some of the actions include to: halve, by the year 2015, the proportion of people without access to safe drinking water (reaffirmation of Millennium Development Goal) and to basic sanitation; develop integrated water resources management (IWRM) frameworks, and implement water management action plans at the country level; and mobilize financial resources to meet the investment needs in the water sector (United Nations, 2002). Taking a 'triple bottom line' approach to society, the economy and the environment focuses those involved in making decisions about urban wastewater systems on the value they add, or destroy, to these interconnected spheres. However, although the principle of sustainable development has gained widespread agreement, it could be argued that many organisations have still not grasped its meaning, and that even fewer have translated sustainability into real on-the-ground action.

The challenges of sustainable development should encourage water service providers to fundamentally re-examine the ways in which water, stormwater and wastewater are managed, and gradually shift away from the predominant end-of-pipe philosophy (sewer networks leading to large treatment plants) towards a more integrated, holistic and ecological approach to 
environmental, economic and societal issues (e.g. Tjandraatmadja et al, 2005). However, there may be irresolvable differences between adopted solutions that are adjudged 'feasible' by the water service providers and those that are sustainable (Starkl and Brunner, 2004; Lundie et al, 2004).

A wide range of tools are currently being applied to assess sustainability within the urban wastewater sector. Many of these can advance the assessment of urban wastewater projects by utilising a multi-disciplinary and integrated process. These include determining, for example, the Best Practicable Environmental Option (BPEO), using Best Available Technology (BAT), the use of Life Cycle Assessment (LCA), Practical Minimum Energy Requirements, Whole Life Costing (WLC), Ecological Footprinting, Integrated Environmental Impact Assessment (IEIA) (Soderberg \& Karrman, 2003) and Strategic Environmental Assessment (SEA) in the European Community (e.g. Malmqvist et al, 2006). Many of these approaches can influence project development by helping to identify design alternatives that are technically viable, more environmentally and socially acceptable, and simultaneously provide opportunities to improve stakeholder participation. However, the greatest power in the use of these tools comes when they can feed into a holistic sustainability assessment framework, as individual tools can, by themselves, only achieve a partial representation and assessment of the components of sustainability (e.g. Kapelan et al, 2005).

A major area of concern for much of the urban wastewater community is the demand for an increase in stakeholder dialogue and stakeholder-sensitive decision-making processes. Whilst there are examples of 'involvement' in Europe (e.g. Chen et al., 2004), wider stakeholder participation is specified in the European Union's Strategic Environmental Assessment (SEA) Directive and the Water Framework Directive (WFD) and more than involvement is essential to deliver water systems that are 'bought into' by communities under what is known as the 'Lisbon 
Agenda' which is also promoting economic growth and jobs. In addition, institutional and governance systems need to support good decision making by being adaptable and flexible. Too often these are constrained so that the more sustainable option is precluded even from the outset (Starkl \& Brunner, 2004). There are, however, good examples from around the world as to how best to engage communities (e.g. Sharpin et al, 1999; Geldof, 2005).

A series of projects have been underway over a period of some 10 years in the UK working with the water industry to encourage the inclusion of sustainability considerations in decision making, particularly in relation to asset management and associated investment. These have considered firstly the disposal of domestic sanitary waste (Ashley et al, 2005), then the management of water infrastructure assets (Ashley et al, 2004) via a guidebook, and are now tackling how best to select options for water and wastewater services for new developments (Ashley et al, 2006). This paper considers two main case studies used in the development of the asset management decision support system, SWARD (Sustainable Water industry Asset Resource Decisions), and in particular the way in which sustainability has been included in the decisions regarding investments using a multi-criteria approach based on environmental, social, technical and economic supporting indicators.

\section{Sustainability Criteria for Urban Wastewater Systems}

Most approaches to sustainability assessment utilise criteria on which to base the assessment. Criteria unfortunately have different meanings in the various applications available. Here they are defined as the set of factors that may be used to assess which of a range of options, in this case for the development of water service provision, offers the greatest contribution to achieving sustainability objectives (Foxon et al., 2002). Criteria differ from principles, which are normative definitions or goals for sustainability and do not change with time. Indicators measure the past and current values of specific criteria, and may be used to set standards against which future 
performance can be assessed. A major difficulty in this approach is that different individuals do not necessarily share the same standpoint on sustainability, nor do they buy-in to the use of predefined criteria and indicators as a means of informing decisions about water and wastewater systems (e.g. Brunner \& Starkl, 2004; Sahota \& Jeffrey, 2005). Nonetheless the use of multicriteria with supporting indicators, pre-defined by consensus of all stakeholders, has the advantage of being both inclusive and comprehensive in ensuring that all aspects of sustainability are addressed in decision making. Most sustainability decision support tools currently follow this approach (Kapelan et al, 2005)

\section{Criteria}

There have been several recent attempts to produce a structured classification of sustainability criteria and indicators specifically related to the performance of water/stormwater/wastewater services (Ashley et al., 2001; Lundin, 2002; Lundie et al, 2003; Malmqvist et al, 2006), although not all of these set out specifically to inform sustainability (e.g. Matos et al, 2003). 'Indicators' of sustainability are currently used to define how well system changes (developments) in terms of pre-defined criteria (and hence principles) are tending toward or away from greater sustainability. Problems when devising sustainability criteria include the fact that they must encompass all aspects of human and natural systems if they are to truly relate to sustainability, and that they have disparate and incommensurate units of measurements. If the criteria and indicator approach is taken, there will typically be complex multi-criteria and multi-objective trade-offs within a subjective decision-making framework.

The UK government originally defined sustainable development as "ensuring a better quality of life for everyone, now and for generations to come" (Department of the Environment, Transport and the Regions, 1999), and a set of national indicators were developed based on four guiding principles. The revised strategy for sustainable development - Securing the Future - sets out a 
new framework covering the period to 2020 that includes guiding principles, priorities for action and a new set of 20 high-level indicators to monitor the key issues at a UK level (Defra, 2005). Water UK, the trade body for all UK water service providers, originally developed a set of 25 indicators to measure progress towards 'environmental' sustainability (Water UK, 2000). These have been extended to encompass a broader definition of sustainability to include social and economic facets (Water UK, 2004). The indicators serve a useful purpose by presenting an aggregate national picture of trends towards, or away, from sustainability, but are less useful in guiding future decision making, particularly with the uncertainties typical of climate change.

Several sets of generic sustainability criteria and indicators have been proposed for water services, mostly in Europe (e.g. Jeppsson et al., 1998; Lundin, 1999; Lundin and Morrison, 2002; Westrell et al., 2002; Lundie et al, 2003; Malmqvist et al, 2006). Researchers in the Netherlands constructed an overview of assessment methods and criteria used in contemporary publications for the comparison of technologies with respect to sustainability (Balkema et al., 2002; Balkema, 2003). A set of sustainability criteria were proposed in which the demands of the end user are translated into functional criteria that have to be fulfilled by the technology. There is a danger that the latter promotes the idea of selecting a BAT, that is presumed to be 'the best' when it has been evaluated on a very limited criteria set (e.g. Starkl and Brunner, 2004). Lundin (2002) considers using a life cycle perspective on all aspects of Sustainable Development to develop adequate procedures and frameworks for indicator selection, despite the uncertainties in doing this and this has now been finalised in the Swedish 'Urban Water' programme (Malmqvist et al, 2006).

The International Hydrological Programme (IHP) together with the American Society of Civil Engineers (ASCE and UNESCO, 1998; Loucks and Gladwell, 1998) have taken perhaps the most comprehensive and holistic approach, providing sustainability criteria and guidelines that 
cover: design, management and operation of the physical system, the environment and ecosystems, economics and finance, institutions and society, health and human welfare, and planning and technology.

\section{Application of Criteria}

Despite these various attempts to develop sustainability criteria for use in planning and managing urban water systems, it is clear that most water service providers are in need of a set of 'generic' criteria, informed by other sustainability principles and indicators that are of more direct use in assessing development options. However, defining the appropriate criteria may be problematic and may not be agreed prior to decisions having to be taken (e.g. Wrisberg et al, 2002).

Starkl and Brunner (2004) refute the idea that any generic criteria should be used in an integrated assessment of sustainability. They argue that not only is it not possible to define such criteria, but that a pre-defined decision management process that purports to include sustainability is undesirable, as decision makers should themselves be forced to select what are appropriate criteria and decision making frameworks within the context in which they are working. This is expected to ensure greater transparency and accessibility to the processes and outputs for a wider range of stakeholders. Nevertheless, there are many examples of standardised approaches that include both fixed criteria and a fixed framework, although the latter may be dynamic (e.g. Trousdale and Gregory, 2004). One benefit of a defined framework is that it can ensure that all dimensions of sustainability are properly accounted for. In addition, it may be easier to compare across infrastructure or service sectors. Often, the interactions between different sectors, e.g. energy, transport, solid waste, etc., with burdens and benefits between these, are overlooked or oversimplified in current sustainability assessments. 
It is clear that there are advantages and disadvantages of using predefined and/or decision specific criteria and whilst there is a need for a framework for support of sustainability decisions to ensure that all facets of the decision are considered, the framework must include some flexibility in the selection of criteria. This requirement was a key influence on the development of the processes described here.

A major requirement when developing a set of criteria is buy-in from the stakeholders. Where this is for a particular sector, such as the water industry, this buy-in is required at all levels of organisations, particularly at the highest levels. Ideally buy-in should also be extended to include all other stakeholders affected in and by the decisions being made. However, the development of such a widely acceptable set of criteria would require significant resources. Hence the work reported here for the SWARD project has concentrated on determining appropriate criteria for the water service providers, with only limited engagement of the wider community. However, wider engagement was a major aspect of the earlier projects carried out by the project team (Ashley et al, 2005) and the results from these community based studies were utilised in the follow-on SWARD project. The emphasis in the work reported here was to develop criteria that were sufficiently comprehensive and also meaningful for the decision makers in the water service industry to allow them to include sustainability in their day-to-day decision making. At the outset of the project, the Scottish Water industry were seeking, firstly to better understand what sustainability meant in their business and also a better means of including these considerations in their activities.

\section{The SWARD Project}

The Sustainable Water industry Asset Resource Decisions (SWARD) project began by exploring the difficulties that the water service providers' were facing when making asset investment decisions, particularly the way in which sustainability considerations were included in 
these processes. The primary objective of the project was to provide a means whereby water service providers could include the principles of sustainability within the decision-making processes in an effective and transparent manner, and which could fit with contemporary decision-making processes. The multi-disciplinary SWARD team comprised researchers from five UK universities, with collaborators from the Scottish water authorities (now Scottish Water), English water companies and water professionals from Romania and Australia (Ashley et al., 2004).

There were four main aspects to the SWARD project (Figure 1):

- Decision mapping (Bouchart et al., 2002; Ashley and Hopkinson, 2002).

- Production of the SWARD Guidebook (Ashley et al., 2002b; Ashley et al, 2004); and

- Demonstration of the Guidebook use via case study examples (Ashley et al., 2001; 2002b).

- Trialling of the criteria with a range of decision makers (Oltean-Dumbrava et al., 2004). Each of these project stages is described below.

\section{Decision Mapping}

A process of decision mapping was initially undertaken with Scottish and English water service providers. The techniques utilised fly-on-the-wall attendance at Value Management (VM) workshops, questionnaires, semi-structured interviews with decision makers and project participants, content analysis of documentation, focus groups and SWARD workshops (Bouchart et al., 2002, Gilmour et al., 2005). A variety of decision-making situations were used to identify how the water industry made decisions and how sustainability was considered. The results suggested the use of a relatively narrow set of economic and technical criteria, mainly related to costs, risk, environmental impact and maintaining flexibility and build quality. Although there were differences in detail between the ways in which organisations included sustainability considerations in their decision-making, the approaches used were sufficiently 
generic to indicate that a flexible set of decision support processes would be useful across a range of organisations (Foxon et al, 2002).

\section{The SWARD Guidebook}

Building on the decision mapping, a Guidebook was developed that would act as a practical tool to assist with the explicit inclusion of sustainability in the decision-making process (Ashley et al., 2004). The SWARD Guidebook contains a framework that comprises a suite of decision support

processes that can be used by water service providers to explicitly incorporate sustainability considerations into their decision-making procedures, through the use of sustainability criteria, indicators and processes. The decision support processes have been designed to expose where the judgement and preferences of the various stakeholders in relation to the criteria have been utilised in making decisions. The Guidebook outlines the following seven iterative phases:

1. Review of performance and definition of decision objectives.

2. Generation of options.

3. Selection of appropriate criteria and indicators relevant to the decision in question and the options under consideration.

4. Collection of data and generation of information for each option and each criterion, together with risk evaluation results.

5. Analysis of options using weightings and ranking of results where appropriate and risk assessment/sensitivity analysis.

6. Selection of the 'preferred' option using some form of utility or multi-criteria assessment.

7. Implementation of the option and post project monitoring and feedback.

The SWARD primary criteria were originally generated through the information obtained from focus groups with the decision makers and decision-mapping exercises above, along with a 
review of the relevant literature. The wider stakeholder community was not explicitly included, other than where this was directly relevant as in the sanitary waste case study, where municipal authorities, environmental regulators, public health specialists and the public were essential participants. However, as it was the water industry decision makers who would ultimately be responsible, their views were considered paramount. This process evolved four criteria groups: environmental, social, economic and technical. It should be noted that the precise categorization of which criteria belong to which group is not important provided all of the primary criteria are included in any assessment. Within each criteria category (economic, environmental, social and technical) there are a small number of primary criteria (see Table 1). These were deliberately kept to a minimum number in order to help reduce the number of 'variables' that a decision maker would have to cope with when making a decision. Under each of the primary criteria, a larger number of secondary criteria are specified. These are defined quantitatively or qualitatively by indicators that may be used collectively to assess the likely performance of the system for the particular development option under scrutiny, in order to assess whether it is moving towards, or away, from greater sustainability. The criteria aim to serve a specific purpose - as an inclusive, generic set which can help to guide water service providers and their stakeholders in selecting a more specific set of criteria for use in comparing a range of options for meeting given objectives (Foxon et al., 2002). The criteria are dynamic and will be continually reviewed as knowledge about the organisation, regulators, regulations and customers and systems change. The accuracy in the analysis of indicator data relies on the expertise within the project team. For this reason it is vital that the correct team of professionals is brought together to gather data and generate information. If sustainability becomes the foundation of decision-making then the traditional decision teams (technical and economic) must be enhanced to include the necessary multi-disciplinary expertise, especially social and environmental. Although the core decision maker group was the UK water industry, the primary criteria have since been trialled in a variety of decision maker situations, including in the USA 
with a range of engineers under the auspices of the USEPA. Despite certain cultural differences in understanding precisely what certain criteria are, the initial SWARD list has been sustained and is being used in the latest WaND (Water cycle management for New Developments) project (Ashley et al, 2006).

The social criteria are perhaps the most difficult to deal with, particularly as a number of these are qualitative. Where possible, collecting information for these was via quantitative surveys using focus groups or questionnaires and criteria that could be measured in this way were favoured where possible. The earlier sanitary waste project (Ashley et al, 2005) had used the quantitative methods extensively and the definition of the relevant criteria and associated indicators was developed from these earlier studies and additional consultation with the key stakeholders, coordinated by the behavioural scientists in the project team. However, in the various case studies different levels of detail were used for the social criteria dependent upon the resources available to work with the communities involved to develop a deep understanding of the issues and possible solutions. In the second phase sanitary waste project (Case study I, 3.5 below) for example, special display material was produced and individual households visited. Whereas for case study I, social criteria were assessed subjectively in expert discussion, case study II took due cognisance of the more detailed results.

\section{Use of the SWARD Guidebook for Wastewater Case Studies}

The SWARD decision support processes are illustrated within the Guidebook by case studies of a range of decision-making needs. These include: examining whether an existing service can be provided in a better way; planning how to manage assets/infrastructure; deciding whether a new service should be provided; making a choice between different methods of providing a service and choosing where to site a new service. Case studies that illustrate two of these types of decision are described below and these have been included to illustrate both the range 
of application and the flexibility of the SWARD processes. Additionally, the decision mapping process had shown that social criteria were rarely used in water asset decisions, therefore there is a focus in the case studies on the selection of social criteria and the impact of these in the data collection and analysis phases. Case Study I demonstrates appropriate criteria and indicators for strategic decision making, Case Study II demonstrates a full application of the processes to assess a range of project options.

Case Study I - Is it sensible to provide sewers to all properties?

This case study addresses the need for the provision of new sewers where currently sewage may be being disposed of to local on-site systems such as septic tanks. The environmental and other burdens of constructing and operating new sewers may outweigh the benefits. In other sectors such as water supply, the application of life cycle techniques can provide some initial idea as to these impacts (e.g. Horvath, 2005).

Approximately $4 \%$ of domestic properties in England and Wales are not connected to the public sewerage system. Section 101A of the Water Industry Act 1991 requires that sewerage undertakers provide a public sewer (first time sewerage) to replace private wastewater systems for domestic premises where there are environmental problems from existing systems and where it can be shown that a public sewer is the cost effective solution. In many other European countries the sewer network is less well established and the requirements arising from the implementation of the Urban Wastewater Treatment Directive (European Commission, 1991) are resulting in massive investments to introduce new 'first time sewerage' provisions.

Systems in place for sanitary drainage for unconnected properties include private cesspools, septic tanks, or small-scale private sewage treatment systems or novel 'people's sewers' 
(Connelly, 2005). In the USA, for example, over $30 \%$ of new developments have on-site sanitation based on the EPA's on-site manual (EPA, 2002).

Sewers may conceivably be one of the greatest innovations in the development of mankind. Since construction in the densest European cities in the industrial revolution, sewers have virtually eliminated waterborne disease (Juuti \& Katko, 2005). Nonetheless conventional waterborne sanitary wastewater systems may have unsustainable features, including inefficient water and pollutant transfer, energy use (direct and embodied), material (particularly nutrient) loss, and sensitivity to under and overloads. A seemingly local sustainable sewerage development may lead to non-sustainable regional consequences, and its high energy and material consumption may lead to non-sustainable global development (Varis and Somlyódy, 1997; Tjandraatmadja et al, 2005). The use of water carrier systems for disposal of blackwater, utilising large infrastructure (sewers and end of pipe treatment plants), is the prevailing UK (and EU) approach, and the use of alternative types of system is not straightforward due to space considerations, little knowledge about risks and building regulations and standards (Balkema, 2003). It is technologically possible for example, to deal locally with blackwater in many rural situations as is being practiced in Sweden, Germany (Otterpohl, 2001), Australia and the USA (EPA, 2002). There are doubts about the social sustainability of such approaches in countries like the UK where this would shift the burden of responsibility to local householders, and there are potential increased cost problems both for installation and long-term operation. Clearly deciding when and where on-site sanitation is appropriate and the most sustainable option is not straightforward.

In the UK, guidance notes have been produced to assist sewerage undertakers to determine whether the duty to provide first time sewerage has arisen (DoE, 1996). The criteria to be used when assessing the case for provision in an individual locality are presented in the guidance 
under the broad headings of 'technical' and 'economic' factors. However, the guidance does not suggest any weighting system to be applied to the criteria, and recommends that in cases where assessment is complex, sewerage undertakers use their own appropriate system to determine whether to provide connection to a public sewer. The SWARD process offers an alternative method of approaching the problem of whether to connect a community to the main sewerage system through the inclusion of sustainable development objectives in the decisionmaking processes, through the use of its criteria and indicators. An example of the social criteria used in the first time sewerage case study is shown in Table 2 . The criteria chosen can be applied to all of the options for private sewerage and first time sewerage, as well as more novel methods of wastewater management, ensuring a more holistic comparison of the various choices.

The Case Study identified a range of options available for reducing problems caused by the existing sewerage arrangements, including: reconstruction of the existing private system; connection to a public sewer; provision of new small treatment works (or coastal outfall); or more novel techniques (e.g. settled sewerage), an approach used in parts of Australia (Sharpin et al, 1999). In any decision scenario, a range of tests would be undertaken to determine the options that are feasible and these may lead to the screening out of some of the options. Involving the community in the decision as to which option is preferred encourages accountability and a sense of local agency, something of great importance in isolated rural communities. Local communities will be in different stages of preparedness to adopt public sewerage or other options. Some communities are genuinely not ready for action, and so resources may need to be directed to education and the building of public support (Brown et al, 2005). The involvement of a range of stakeholders in the decision making process is enhanced through the application of the SWARD generic criteria. The criteria shown in Table 2 involve indicators that require the engagement with the wider community in their assessment. 
Techniques such as focus groups, liaison with community representatives, and door-to-door surveys can be used to ensure a realistic evaluation of the communities' views of the value of the indicators. However, the involvement of the wider community does introduce additional complexity and resource requirements, particularly the need to involve social scientists in the data collection and analysis as discussed in case study II below.

\section{Case Study II: Can domestic sanitary waste be managed more sustainably?}

This case study illustrates the full application of the SWARD process to examine the relative sustainability of a range of options for the management of domestic sanitary waste currently disposed of via the toilet. The study described here was a further development of an earlier study that considered only two options (Ashley et al., 2005). Disposal of sanitary waste via the toilet is habitual in the UK, USA and a number of other developed countries and stems from the historical link associating health risks with human waste (hygiene). Recent concerns about excessive water use for toilet flushing, and the downstream costs of dealing with these solids have forced a re-appraisal to be made of this method of disposal. Disposal of sanitary waste via the toilet causes many problems for wastewater system operators, including blockages, increased requirement for maintenance due to damage to screens at overflows and to equipment at treatment plants, increased loads to treatment plants, and significant impacts on the environment via overflow discharges and 'escape' through screens (Ashley et al., 2004).

The case study catchment was a small coastal town (population c. 1500) in Scotland with 626 domestic properties, mostly detached or semi-detached. These have large impermeable roof areas, and the majority also have drives of which about $30 \%$ are porous. A large portion of the town's developed area is on high ground above the original coastal floodplain. The steep gradient down to the wastewater treatment works therefore affects the drainage patterns of a large proportion of the impermeable catchment. Under storm conditions ponding is prevalent on 
flat impermeable areas. In sloping areas surface water flows freely, often avoiding catchbasins and finding its own route to vegetation or to small watercourses. The catchment is served by $80 \%$ combined and $20 \%$ surface water sewers.

The water industry and other stakeholder collaborators were involved in each of the phases of the case study and provided feedback and validation on all aspects of the work. The involvement of a range of stakeholders in the decision making process creates the possibility of a diverse range of opinions on the values attributed to indicators and on their relative weightings in the analysis. These issues must be addressed in Phase 1 of the process, the review of performance and definition of decision objectives and in Phase 7, implementation of the option and post project monitoring and feedback. The approach adopted in the case study was to define the nature of the decision maker at Phase 1 of the study and then to utilise weightings in the initial analysis of data that reflected mainly the decision makers' values and perceptions. Additionally in Phase 1, the decisions makers' attitude towards sustainability and their use of the outcome of the analysis must be determined. Phase 7 , implementation of the option and post project monitoring and feedback, then allows a re-evaluation of the data analysis, through sensitivity testing to evaluate the influence alternative weightings based on wider stakeholder perceptions. Phase 7 also allows the decision maker to reflect on the analysis and then to make a decision either based fully in the results of the SWARD analysis, where sustainability was their predominant driver, or to consider the results of the assessment along with other issues that were not assessed using in the SWARD criteria. In Case Study II the decision maker was defined as the water services provider and, due to the exploratory nature of the case study research, they chose to be guided by the SWARD assessment in the final decision stage in Phase 7 rather then being bound by it. 
The case study had the aim of 'managing the number of sanitary waste items escaping to the environment via storm overflow discharges in a way that is likely to be the most sustainable'. Six options were generated for assessment (Table 3). The different approaches address the management of sanitary waste at different points in the system, and can be grouped into three generic methods: (A) End of pipe; (B) Habit change; and (C) Spill reduction. The existing hydraulic system was computer modelled to incorporate each option individually to provide information for these different scenarios.

Examples of the social criteria used in the case study are presented in Table 4. These were derived from earlier studies in the first stage sanitary waste project as outlined in Section 3.1 together with expert discussion with the decision makers and the social science experts in the project team. As discussed, weightings were determined to reflect the perceptions of water services providers but nevertheless a comprehensive evaluation of potential weightings was required. The criteria were discussed and validated at a meeting with senior representatives from the water industry. A workshop was also held involving members of staff from another water service provider with the aim of weighting the importance of the selected criteria in the decision making process. A further meeting with a key water industry 'decision maker' allowed data to be obtained on preferences, indifference values and veto levels for all the criteria needed for input into a range of Multi-Criteria Analysis (MCA) models. A very wide range of data collection and analytical methods were utilised for the case study, including Life Cycle Assessment (LCA) (Gouda et al., 2002), hydraulic modelling, social surveys and workshops with a wide range of stakeholders to determine appropriate values for the social indicators, and the Multi-Criteria Analysis (MCA) models ELECTRE III, SMART and PROMETHEE (Ashley et al., 2002a). This work was very resource intensive requiring approximately 1 person-year for the LCA and hydraulic modelling, six person-months for social surveys, including door to door surveys in the Case Study community and six person-months for the MCA analysis. This level 
of resources was available for the research study, but the level of resources committed may not be feasible for routine application on decisions of this nature. Further research is required to identify the most parsimonious data set to support robust sustainable decision making in such circumstances.

Options 4, 2 and 5 (retrofit stormwater source control, running the 'Think Before You Flush' educational campaign and sewer rehabilitation) generally occupy the top three ranks in the ELECTRE III, SMART and PROMETHEE analysis. Options 1, 6 and 3 (install $6 \mathrm{~mm}$ screens, fit constricting toilets and install flow storage) were in the lower three ranks. Sensitivity testing was undertaken using a large range of weightings to assess the impact of differing stakeholder perceptions and this demonstrated that the rankings were robust with only minor changes in the rank order of options 2, 4 and 5 .

In Phase 7 of the process, the results of the analysis and the sensitivity testing were considered by the decision maker at a workshop facilitated by the researchers that involved the water service provider and their environmental and economic regulators. There was a consensus that although screening is one of the least sustainable options, the legislative requirement in the UK for $6 \mathrm{~mm}$ aperture screens to be fitted at overflows to meet the minimum discharge requirement for aesthetic pollution was paramount. This requirement is a direct result of the almost ubiquitous disposal of sanitary solids via the toilet, and the subsequent aesthetic pollution of watercourses. In most other European countries other than the UK, screening is largely unnecessary due to differences in sanitary waste disposal habits of the populations. Installing in-sewer storage, a common 'quick-fix' solution used in the UK, was also revealed by the case study to be less sustainable than the three top ranked alternative options (Ashley et al., 2002a). Therefore, the decision maker considered implementation of the most sustainable option, public education to be too risky as there could be no guarantee that toilet users would not continue to 
flush sanitary solids, notwithstanding their stated intentions not to do so. Whilst this outcome was disappointing, it was agreed that the sustainability assessment had raised important questions on the policy of screen installation and it was agreed that the water services provider and the environmental regulator would consider further the implications of the Case Study. Nonetheless in the subsequent period, despite investing a lot more resources in promoting habit change in Scotland, the sewerage operator has reverted to the traditional approach and has even abandoned the outcomes of the project, preferring to re-align with the UK-wide 'Bag-itdon't-bin-it' project which was discredited in the detailed research reported here (Brown et al, 2005).

\section{Conclusions}

Business organisations, such as those who provide water services, have a major role to play in influencing how we live and are making advances in delivering corporate sustainability through management of the business case for sustainability. The difficulty is how to operationally transform the vision and strategy into reality. Business success is also recognised as being dependent on environmental and social issues that are 'non-market' and provide infrastructure and essential services that are suited for high quality living and maintaining the health and wellbeing of citizens and encouraging more responsible behaviour across the range of stakeholders (Schaltegger \& Wagner, 2006). The SWARD project has led to a greater understanding of how a wide range of water service providers in the UK currently make decisions and what place sustainability has in these decision processes.

The research has shown that, unfortunately, in most organisations, the selection of options for water, stormwater or wastewater projects is still generally too prescriptive, and current governance, institutional, legislative, regulatory, risk, technological and economic paradigms 
tend to constrain most water service providers into adopting well-tried and tested technologies. The problems are compounded by a very variable commitment to the inclusion of sustainability issues in water service provision across organisations and internal staff turn-over. In the SWARD project for example, hardly any of the key staff from the water service providers who worked on the project remained when it was time to roll-out the SWARD processes. There are also few incentives for water service providers in the UK to include sustainability in their decision processes, despite the main legislation indicating that sustainability should be a major consideration.

The immediate environmental impact of many water service provider activities has been addressed in recent years by huge investments in technologies and processes designed to recover or eliminate pollutants, often involving the use of huge amounts of energy and the generation of excessive residuals, such as sludge. In other areas, the utilisation of traditional large scale solutions such as large storage sewers as currently proposed in London, do not suggest that innovation and an appreciation of the wider impacts of energy use and long-term technology 'lock-in' (where the asset is so valuable it has to be used even though it may be unsustainable) have become adequately appreciated by those making decisions (Ashley et al, 2006a).

The research described here has presented a set of criteria that will ensure that the main elements of sustainability are included in water asset related decision making. It has also shown that it is possible to incorporate social criteria more fully in the decision making process and to involve the perceptions of a wide range of stakeholders in sustainability assessment, although it is acknowledged that inclusion of the wider stakeholder community was undertaken within a context that was largely defined by the key decision makers, the water services providers. However, there is growing interest in stakeholder engagement and the challenge to water 
service providers remains - how best to consult, inform, educate and mobilise a wide range of stakeholders in the decision making process? The ever-increasing pressure on water service providers to include 'sustainability' within their project planning processes should not be viewed as a constraint, but should be regarded as a fresh opportunity for those involved in urban wastewater planning to contribute to sustainable development. For example, in the UK the Water Act 2003 now imposes a specific duty on all of the major stakeholders delivering water services to properly include sustainability considerations in their activities. The case studies outlined in this paper have illustrated how use of the SWARD processes and sustainability criteria can aid in assessing the relative sustainability of options for a wide range of decisionmaking scenarios. The SWARD framework has been specifically developed to complement, rather than supersede, the current decision making processes used within the water industry, and can help the sustainability aspirations of urban water service providers and their regulators and stakeholders to become fact.

Since SWARD was completed in 2004 , it is apparent that while elements of sustainability have been evident in both the regulatory and service delivery aspects of water service provision, there has not yet been a firm grasp of what this should mean in terms of the performance of the water service providers in the UK nor in terms of how the economic regulator (Ofwat) should set about ensuring adequate incentivisation (e.g. Davis et al, 2005). There are major challenges in balancing service provider survivability, including attractiveness to investors, facing current and future drivers and maintaining or improving services within a cost-limited framework that now need to be faced if water is to be provided and managed as part of society's need to become sustainable. This is perhaps even more important if these services are to be provided adequately to those in the world with the greatest need (WHO/UNICEF, 2006).

\section{Acknowledgements}


The authors would like to thank the following for contributing to the SWARD project: Steven Cavill and Gary Mcllkenny at Heriot-Watt University; Timothy Foxon, Matthew Leach and Peter Pearson at Imperial College London; Sarah Hendry, Jim Moir and William Samson at the University of Abertay Dundee; and Hazem Gouda at Southern Water. The authors would like to express their gratitude to the Engineering and Physical Sciences Research Council and the UK Water Industry for funding the SWARD and Whole Life Costs of Sewerage projects.

\section{References}

ASCE Water Resources Planning and Management Division and UNESCO International Hydrological Programme IV. Project M-4.3 Task Committee on Sustainability Criteria (1998). ASCE Reston, Virginia, USA.

Ashley, R., Blackwood, D., Butler, D. and Jowitt, P. (2004) Sustainable Water Services: a procedural guide. International Water Association Publications. ISBN 1-843390-65-5.

Ashley, R., Blackwood, D., Souter, N., Hendry, S., Moir, J., Dunkerley, J., Davies, J., Butler, D., Cook, A., Conlin, J., Squibbs, M., Britton, A. and Goldie, P. (2005). Sustainable disposal of domestic sanitary waste. ASCE Journal of Environmental Engineering 131 (2), 206-215.

Ashley, R., Blackwood, D., Butler, D., Jowitt, P., Oltean-Dumbrava, C., Davies, J., et al. (2002b). Making more sustainable decisions for asset investment in the water industry Sustainable Water industry Asset Resource Decisions - the SWARD project. In Global Solutions for Urban Drainage: 9ICUD, Eric W. Strecker and Wayne C. Huber (eds)., Proceedings of 9th International Conference on Urban Drainage, Portland, Oregon, September 8-13, Reston, V.A., ASCE, ISBN 0-7844-0644-8.

Ashley, R., Gilmour, D., Oltean-Dumbrava, C., Smith, H., Gouda, H., Cavill, S. and Blackwood, D. (2002a). Comparative sustainability of the options for the management of sanitary solids. 3rd International Conference on Sewer Process and Networks, Paris, 15-17 April. 
Ashley, R. and Hopkinson, P. (2002). Sewer systems and performance indicators - into the 21st Century. Journal of Urban Water 4 (2), 123-136.

Ashley, R., Smith, H., Jowitt, P., Butler, D., Blackwood, D., Davies, J., Gilmour, D. and Foxon, T. (2001). A multi-criteria analysis/risk management tool to assess the relative sustainability of water/wastewater systems: SWARD (Sustainable Water Industry Asset Resource Decisions), Proceedings of the First National Conference on Sustainable Drainage, Coventry, UK, 18-19 June, ISBN: 1903818060.

Ashley R M., Butler D., Hurley L., Memon F. (2006). Criteria and indictors in delivering sustainable water systems: From sustainable water asset resource decisions (SWARD) to water cycle management for new developments (WaND). In: DayWater. Ed. Thevenot D. IWA Publishing. (in press).

Ashley R M., Tait S J., Styan E., Cashman A. (2006a). Sewer system design moving into the 21st century - a UK perspective. Proc. 7th Int Conf on Urban Drainage Modelling/4th Int Conf on Water sensitive urban design. Ed. Deletic A., Fletcher T. ISBN 0-646-45903-1. Vol. 2 p559-566.

Balkema, A.J. (2003). Sustainable Wastewater Treatment - developing a methodology and selecting promising systems. PhD Thesis, Technische Universiteit Eindhoven, ISBN 90386-1805-0, 210 pp.

Balkema, A.J., Preisig, H.A., Otterpohl, R. and Lambert, F.J.D. (2002). Indicators for the sustainability assessment of wastewater treatment systems. Urban Water 4 (2), 153-161.

Bouchart, F.J-C., Blackwood, D.J. and Jowitt, P.W. (2002). Decision Mapping: Understanding decision making processes. Civil Engineering and Environmental Systems 19 (31), 187-207.

Brown R R., Sharp L., Ashley R M. (2005). Implementation impediments to institutionalising the practice of sustainable urban water management. Proc. 10th Int. Conference on Urban Drainage. Copenhagen. August. (available on CD) [to be published in Water Science and Technology] 
Chen, C.W., Herr, J., Weintraub, L. (2004). Decision support system for stakeholder involvement. ASCE Journal of Environmental Engineering 130 (6), 714-721.

Connelly R W. (2005). Small Bore Sewers: The people's sewer. Water and Wastewater Europe conference. Milan, June.

Cosgrove, W.J. and Rijsberman, F.R. (2000). World Water Vision. World Water Council. Earthscan pub. ISBN $185383730 \mathrm{X}$.

Davis R., Read C., Burston P. (2005). Regulating for a sustainable water sector. Green Alliance. ISBN $095497574 \mathrm{X}$.

Department of the Environment and Welsh Office (1996). Guidance on the Provision of a Public Sewer under Section 101A of the Water Industry Act 1991, Department of the Environment, Water Supply and Regulation Division, April.

Department of the Environment, Food and Rural Affairs (2005). Securing the Future - delivering UK sustainable development strategy. Defra, London.

Department of the Environment, Transport and the Regions (1999). A Better Quality of Life: A strategy for sustainable development for the UK. DETR, London.

Environmental Protection Agency (2002). Onsite Wastewater Treatment Systems Manual. Office of Water, Office of Research and Development, U.S. Environmental Protection Agency.

European Commission (1991). Urban Waste Water Treatment Directive - Official Journal of the Council of the European Communities, (91/271/EEC). Brussels, L135, 30 May.

Foxon, T.J., Mcllkenny, G., Gilmour, D., Oltean-Dumbrava, C., Souter, N., Ashley, R., Butler, D., Pearson, P., Jowitt, P. and Moir, J. (2002). Sustainability Criteria for Decision Support in the UK Water Industry. Journal of Environmental Planning and Management 45 (2), 285-301.

Geldof G. D. (2005) Coping with complexity in integrated water management. On the road to Interactive Implementation. Published by Tauw, Deventer. ISBN 90-76098-04-2 
Gilmour, D., Blackwood, D. and Picken. K. (2005). Stakeholder involvement in wastewater treatment design. Proceedings $10^{\text {th }}$ International Conference on Urban Drainage, Copenhagen, $21-26$ August.

Gouda, H., Ashley, R.M., Gilmour, D. and Smith, H. (2002). Life Cycle analysis and sewer solids. 3rd International Conference on Sewer Process and Networks, Paris, 15-17 April.

Horvath A. (2005). Life-cycle Energy Assessment of Alternative Water Supply Systems in California. Report from PIER-EA Exploratory Grant contract, University of California, Berkeley. International Standardization Organization (1997-2000). Environmental Management - Life Cycle Assessment - Principles and Framework. International standard ISO 14040-3, 1st ed. 1997-06-15. Geneva: ISO.

Jeppsson, U., Hellstrom, D. and Karrman, E. (1998). Systems analysis of sustainable water management, MISTRA project report, October.

Juuti P., Katko T. (2005) (Eds.),. Water, time and European cities. EU WaterTime project. EU Contract No: EVK4-2002-0095. http://europa.eu.int/comm/research/rtdinf21/en/key/18.html.

Kapelan Z., Savic, D., Walters G. (2005) Decision-support tools for sustainable urban development. Proc. Inst. Civ. Engrs. UK. Engineering Sustainability. 158, No. 3, 135-142.

Lundie S., Peters G., Beavis P. (2004). Life cycle assessment for sustainable metropolitan water systems planning. Environmental Science and technology 38 (13) pp 3465-3473

Lundie S., Peters G., Beavis P. (2005). Quantitative systems analysis as a strategic planning approach for metropolitan water service providers. Wat. Sci. Tech. Vol. 52, No. 9, pp11-20.

Lundin, M. (1999). Assessment of the environmental sustainability of urban water systems, Licentiate Thesis, Dept. of Technical Environmental Planning, Chalmers University of Technology, Goteborg, Sweden.

Lundin, M. (2002). Indicators for measuring the sustainability of urban water systems - a life cycle approach. PhD Thesis, Environmental Systems Analysis, Chalmers University of Technology, Goteborg, Sweden. 
Lundin, M. and Morrison, G. (2002). A life cycle assessment based procedure for development of environmental sustainability indicators for urban water systems. Urban Water 4 (2), 145152.

Loucks, D.P. and Gladwell, J.S. (Eds.) (1998). Sustainability criteria for water resource systems, International Hydrology Series, Cambridge University Press.

Malmqvist P-A., Heinicke G., Kärrman E., Stenström T A., Svensson G. (2006). (Eds.) Strategic Planning fo Sustainable Urban Water Management. IWA publishing. ISBN13: 9781843391050 .

Matos R., Cardoso A., Ashley R M., Molinari A., Schulz A., Duarte P (2003). Performance Indicators for Wastewater Services - IWA Manual of Best Practice. International Water Association. ISBN 1900222906

Oltean-Dumbrava, C., Ashley, R.M., Alker, S., Smith, H. and Gilmour, D. (2004). The relative merits of different multi-criteria decision systems used in the context of a sanitary waste case study. Proc. $6^{\text {th }}$ Int. Conf. On Hydroinformatics. 21-24 June 2004, Singapore. (Eds. Liong, Phoon, Babovic) World Scientific Pub. Co. ISBN 9812387870.

Otterpohl, R. (2001). Black, Brown, yellow, grey - the new colours of sanitation. Water 21. October.

Schaltegger S., Wagner M. Eds. (2006). Managing the Business Case for Sustainability. Greenleaf pub. ISBN 10: 1-874719-95-0.

Sahota P S., Jeffrey P. (2005) Decision-support tools: moving beyond a technical orientation. Proc UK Institution of Civil Engineers: Engineering Sustainability, Vol 158, ES3, 127-134.

Sharpin, M, Barter, S., and Csanki, S (1999) Stormwater Management Planning in New South Wales Australia. Proceedings of 8th International Conference on Urban Storm Drainage, Vol 4 pp2006-2014, Sydney, Australia. 
Soderberg H., Karrman E. (2003). MIKA Methodologies for integration of knowledge areas. The case of sustainable urban water management. Goteborg: Department of Built Environment and Sustainable Development, Chalmers University of Technology.

Starkl, M. and Brunner, N. (2004). Feasibility versus sustainability in urban water management. Journal of Environmental Management 71 (3), 245-260.

Tjandraatmadja G., Burn S., McLuaghlin M. , Biswas T. (2005). Rethinking urban water systems - revisiting concepts in urban wastewater collection and treatment to ensure infrastructure sustainability. Wat. Sci.Tech. Vol 5, No. 2 pp 145-154.

Trousdale, W. and Gregory, R. (2004). Property evaluation and biodiversity conservation: Decision support for making hard choices. Ecological Economics 48, 279-291.

United Nations (2002). Global Challenge Global Opportunity: Trends in Sustainable Development. United Nations Department of Economic and Social Affairs, World Summit on Sustainable Development, Johannesburg, August.

Varis, O. and Somlyódy, L. (1997). Global urbanization and urban water: can sustainability be afforded? Water Science and Technology 35 (9), 21-32.

Water UK (2000). Towards Environmental Sustainability: Indicators for the Water Industry. Water UK, Ipswich.

Water UK (2004). Sustainability - broadening the perspective. UK water industry sustainability indicators 2002/2003, Water UK, London.

Westrell, T., Bergstedt, O., Heinicke, G. and Kärrman, E. (2002) A systems analysis comparing drinking water systems - central physical-chemical treatment and local membrane filtration. Water Science and Technology: Water Supply 2 (2), 11-18.

WHO/UNICEF (2006). Meeting the Millennium Development Goals drinking water and sanitation target. WHO library. ISBN 9241563257 
Wrisberg N., Udo de Haes H A., Triebswetter U., Eder P., Clift R. (Eds.). (2002). Analytical tools for environmental design and management in a systems perspective. Kluwer pub. ISBN 04020-0626-8. 
Table 1: The SWARD primary (generic) criteria (adapted from Foxon et al., 2002)

\begin{tabular}{lllll}
\hline Category & Economic & Environmental & Social & Technical \\
\hline Criteria & Life cycle costs & Resource utilisation & Impact on risks to & Performance of the \\
& Willingness to pay & Service provision & human health & system \\
& Affordability & Environmental impact & Acceptability to & Reliability \\
& Financial risk exposure & stakeholders & Durability \\
& & Participation and & Flexibility/adaptability \\
& & responsibility & \\
& & Public awareness and & \\
& & understanding & \\
& & Social inclusion &
\end{tabular}


Table 2: First time sewerage case study social criteria and indicators

\begin{tabular}{lll}
\hline Primary Criteria & Secondary Criteria & Indicators \\
\hline Acceptability to & Perceived impact on the environment & \% of customers perceiving \\
stakeholders & Perceived impact on aesthetics/amenity & improved/deteriorating impact \\
& Perceived impact on health & \% acceptability in terms of health risks \\
& Perceived impact on property values & \% perceived increase/decrease on \\
& Acceptability to customers & house prices in the community \\
Participation and & Increase participation and responsibility & \% willingness to change to more \\
responsibility & & sustainable behavior \\
Public awareness & Customer information & Amount of information provided about \\
and understanding & & wider issues? \\
& Awareness of sustainable development & \% of customers with awareness and \\
Impact on risks to & Exposure to infection risks & understanding \\
human health & & Number of affected persons/100,000 \\
\hline
\end{tabular}


Table 3: Summary of the six options, measures and objectives for dealing with sanitary waste

\begin{tabular}{|c|c|c|c|}
\hline Option & Measure & Type of measure & Objective \\
\hline 1 & $\begin{array}{l}\text { Install } 6 \mathrm{~mm} \text { screens on } \\
\text { overflows at treatment works }\end{array}$ & End of pipe & $\begin{array}{l}\text { To screen overflows to constrain solids larger than } \\
6 \mathrm{~mm} \text { to comply with minimum aesthetic pollution } \\
\text { requirements. }\end{array}$ \\
\hline 2 & $\begin{array}{l}\text { Run ‘Think Before You Flush' } \\
\text { public awareness campaigns }\end{array}$ & Habit change & $\begin{array}{l}\text { To encourage change in habits to dispose of } \\
\text { sanitary solids from toilet to solid waste route. }\end{array}$ \\
\hline 3 & $\begin{array}{l}\text { Install flow storage in sewer } \\
\text { network }\end{array}$ & Spill reduction & $\begin{array}{l}\text { To reduce frequency/volume of overflow spills - } \\
\text { reducing the no. of sanitary waste items } \\
\text { discharged to environment. }\end{array}$ \\
\hline 4 & $\begin{array}{l}\text { Retrofit stormwater source } \\
\text { control }\end{array}$ & Spill reduction & $\begin{array}{l}\text { To reduce stormwater entry to the sewer system, } \\
\text { thus reducing overflow spill frequency and volume. }\end{array}$ \\
\hline 5 & Sewer rehabilitation & Spill reduction & $\begin{array}{l}\text { To limit infiltration to sewer system, thus reducing } \\
\text { overflow spill frequency and volume. }\end{array}$ \\
\hline 6 & $\begin{array}{l}\text { Retrofit outlet flow constrictors } \\
\text { on existing toilets/introduce } \\
\text { these to new developments }\end{array}$ & Habit change & $\begin{array}{l}\text { To force a change in disposal habits (exclusion) } \\
\text { switching from toilet to solid waste route. }\end{array}$ \\
\hline
\end{tabular}


Table 4: Sanitary waste case study social criteria and indicators

\begin{tabular}{llll}
\hline Primary criteria & Secondary criteria & Indicator & Method of collection \\
\hline Acceptability to & Acceptability to & \% acceptability (Qualitative) & Door-to door questionnaire \\
stakeholders & stakeholders & & Door-to door questionnaire \\
& Perceived impact on & \% perceiving negative & Consultation with water service \\
environment & environmental impact (Qualitative) & provider staff/SWARD team \\
\hline
\end{tabular}




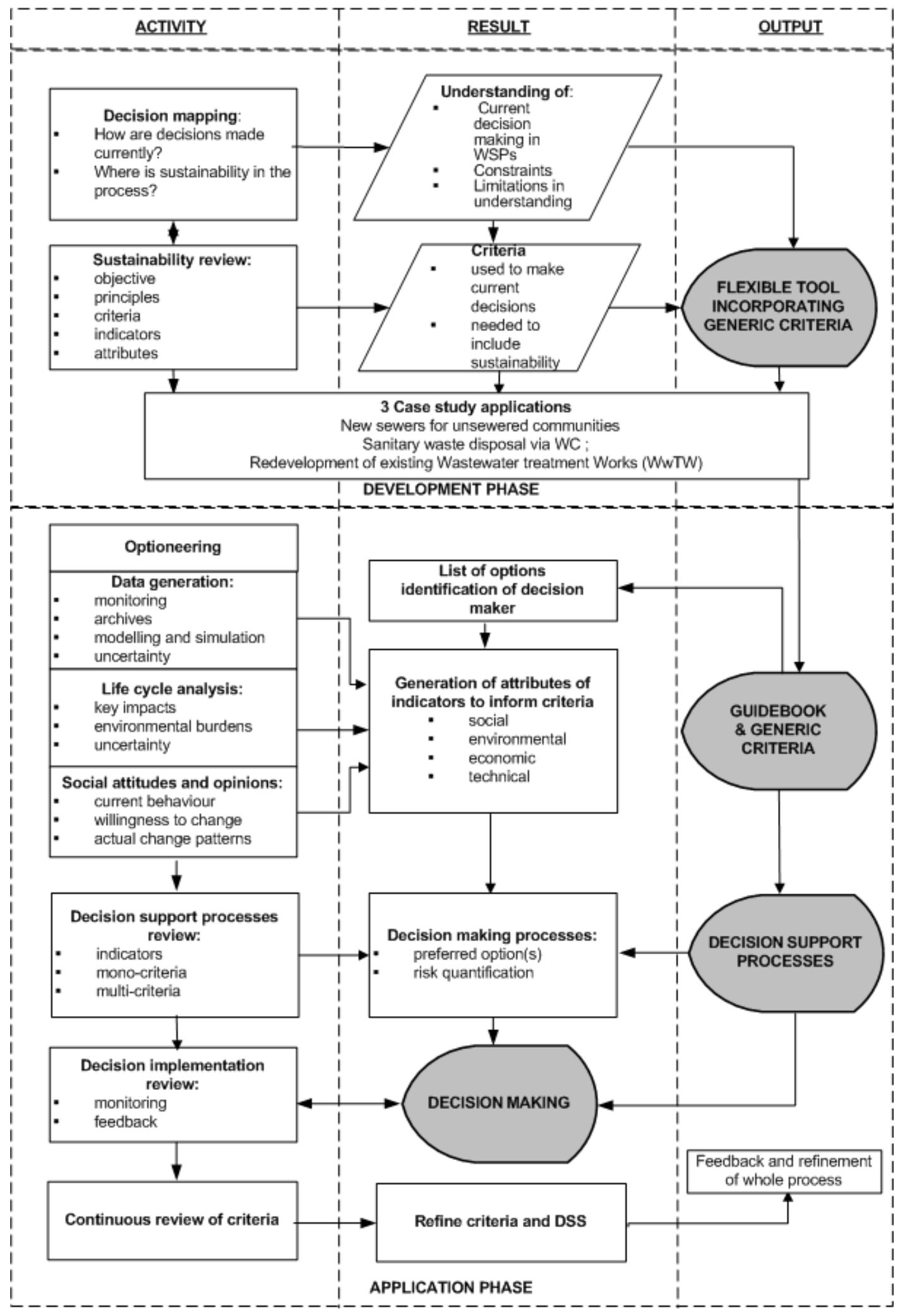

Figure 1: SWARD project activities 